There was tenderness on both sides of the loins, and the movements were limited when beuding forwards. He had some neurasthenic symptoms, and was not fit

CASE 34. - Timberer in a coal mine; aged 53. Date of accident, January, 1911. He was lifting a wagon full of dirt, whon he strained himself and fainted. On recovering he had pains in the back and abdomen, and has fainted. On, recovering he had pains in the back and abdomen, and has not been able to work sinee the accident. He was treated at home by his
loctor for several months and was given liniments. In Jume, 1911, when I first saw him he complained of pains in the back, but his most prominent symptom was that of thirst, dryness of the tongue, and frequent passage of urine. He told me that he was drinking six or seven quarts of water each day in addition to tea and milk, and that he passed water about 20 times a day. He had lost $56 \mathrm{lb}$. in weight since the accident. On examination $I$ found tenderness over the lumbar muscles on both sicles, and the urine showed most marked glycosuria, with a specific gravity of 1036 . Prior to the accident, he only drank three pints of liquids in the day while at work, and passed urine four or tive times. He had never had any illness previous to the accident, and was a most regular worker. Fronl June, 1911, onwards to May, 1912, he was under rigorous diabetic treatment, but while the disease had been arrested there was little progress. The specific gravity of the urine was 1034, with a most definite reaction for sugar. The weight had not altered during these 11 months.

CASE 38.-Pitshaftsman ; aged 42. Date of accident, November, 1911 He was trying to lift up a steel pipe weighing $8 \mathrm{cwt}$. when he strained himself and felt a sudden pain in the back. He cid not give up work at himself and fict a a sudder once, but hished his tirn. He rested for the two next rays and worked the day afterwark tho the another day, when he had to give up because the pain in the back became worse. He was in bed at home for three weeks and was treated with liniments, alter which he had a course of Turkish and electric baths. He started light work in February, 1912, and worked irregularly for several weeks, but eventually was compelled to cease work on account of pain and weakness in the back. In June, 1912, he com plained of pain in the left loin, especially on movement. On examination I found there was tenderuess on the left side of the back in the mid-lumbar region, where the muscles were atrophied. The movements of the back were limited in all directions, and when he bent the back forwards there was pain. There was acute tenderness on pressure over
the last intercostal nerve on the left side. He was only fit for light work on the surface.

\section{EPITHELIAL GRAFTING AS A MEANS OF EFFECTING THE SURE AND RAPID HEALING OF THE CAVITY LEFT BY THE COMPLETE MASTOID OPERATION.*}

By , CHARLES A. BALLANCE, M.V.O., M.S. LoND.; F.R.C.S. ENG.

SURGEON 'TO ST. 'IHOMAS'S HOSPITAL, EIC.

The argument.-Two conditions are essential to the success of operation for the cure of chronic otorrhœa: (1) all disease must be removed ; (2) the large bone wound must be made to heal from the bottom. We may say at once and deliberately that, in the great majority of the cases, all the disease can be removed without injury to important structures. Greater difficulty has been experienced in fulfilling the second condition. Systematic tamponning, either through the unsutured mastoid wound, or through the enlarged meatus, has been employed for this purpose. All who have carried this out are aware how painful it is to many patients and how it wearies both the surgeon and the patient. Whiting, ${ }^{1}$ in his work published in 1906, speaks of the severity of the pain inflicted by dragging out the gauze packing. and of the weary weeks of frequent dressings and irksome details which the intelligent care of mastoid cases requires. Politzer" says: "The duration of the aftertreatment varies from six weeks up to nine months and over. The mean duration is between three and four months." Grunert ${ }^{3}$ says : "In exceptional cases cicatrisation proceeds so smoothly that the entire cavity is healed in from four to six weeks; on an average cicatrisation is complete in three to four months. There are, however, specially unfavourable cases in which, either as a result of constitutional peculiarities or of particularly unfavourable local conditions, this period of time becomes considerably extended." Passow in a thoughtful paper gives statistics from various clinics showing that the average duration of treatment by the tamponning method varied from four to ten weeks in the most favourable instance up to 36 weeks and over. Respecting the most favourable figures quoted he, however, says : "Though Hartmann in the most recent edition of his text-book, when referring to the radical operation, remarks laconically that the healing takes from four to ten weeks, this can really

if A paper read before the International Otological Con 8 iws, $\nu u_{s}$ ton Angust, 1912 . only be taken oum grano salis." Most striking, however, are the figures which he gives respecting the cases operated on in his own clinic at Heidelberg. Of 44 recovered cases 18 were operated on by different methods, but all without Thiersch grafting. In these the average duration of the after-treatment was 20 weeks. The other 26 cases were operated on by a method described in the paper of which Thiersch grafting forms a part. In these the average duration of treatment was 11 weeks. One healed in three and a half weeks, but the majority took over three months to heal.

A visit which I paid some years ago to the otological clinics of Körner, Lucae, Trautmann, Jansen, Schwartze and Grunert, Barth, Politzer, and Bezold, in which I saw hundreds of cases in various stages of treatment by the tamponning method, gave ine the impression that the abovequoted statements give rather too favourable a view of the results of that treatment. I should say that in many of the cases treatment was continued for six or seven months. became, therefore, more than ever confirmed in the opinion that the method I described in $1900^{5}$ presents great advantages over tamponning alone and over the methods of grafting practised before that date by myself and others. ${ }^{6}$ In almost all my cases the bone wound becomes dry in from two to three weeks. When grafting is carried out at the close of the bone operation the tympano-antral cavities are epithelialised immediately, and at the end of ten days it often happens that the further treatment no longer calls for special skill. I never obtained such results without grafting; and I may add that I had a wide experience of mastoid surgery before anyone even proposed to shorten the healing process by grafting. In general surgery skin grafting is carried out in order to hasten the cicatrisation of a wound having a large superficial area, since a large wound to which living epithelial cells are applied heals more quickly than one which has to be entirely covered by ingrowth of epithelial cells from the edges. The wound left after the complete mastoid operation is not only of large superficial extent, but its floor is in great part raw bone, a tissue which heals much more slowly than cloes soft tissue, and is, moreover, much more susceptible of reinfection during the process of healing. The surface of the wound is not flat, but it is so shaped that granulations, if allowed to become exuberant, may cross the cavity and shut off spaces which remain unhealed and which so become a fertile canse of persistent discharge, and so of failure of the operation. When I visited his clinic Jansen, in doing the complete mastoid operation, applied immediately several small grafts, completely sutured the mastoid flap, and treated the case by tamponning through the enlarged meatus. He objected to grafting the tympanum on account of its numerous recesses, which he considered made the proper application of a graft impossible, and also because the graft might throw a veil over the two windows and so prodnce loss of hearing. This fear is not confirmed by experience. 'The sole object of the grafting operation is to expedite the healing of the wound. 'To contend that there is any great difference in the final result is an error, but the more rapid the healing the better for the patient in general and for the hearing in particular. The result of grafting by the method I now use has been, in my hands, so satisfactory in many hundreds of cases that I can strongly recommend it.

The advantages gained by grafting the mastoid cavity are :-

1. Rapid healing of the entire wound, bone, cartilage, and soft parts, on ordinary surgical principles.

2. Immerliate protection of the raw bone surface by a layer of living epithelium, and, in consequence, elimination of the pain and discomfort otherwise incidental to treatment by tamponning and of the liability to reinfection of the bone.

3. Considerable shortening of the time during which specially skilled attendance is necessary. Two weeks after the grafting operation the bone granulations are all covered by visible living epithelium, and the rest of the attendance may safely be left to the family doctor.

4. Improvement in hearing. When the graft has been $c u t$ very thin and successfully applied healing takes place at once under the best conditions. The graft, except its inner layer of living cells, separates by aseptic molecular necrosis, 'The fenestræ become covered by the thinnest possible layer of tissue, and consequently the hearing is generally very 
good, and is certainly much better than when granulation has long been present over the fenestræ.

The above advantages are almost invariably obtained when all bone disease has been removed and the raw bone surface has been covered with a single graft, cut sufficiently thin, and accurately applied. If these conditions have not been fulfilled the method described by me has not been carried out.

The hearing after the complete mastoid operation.Patients naturally always wish to know whether they will thear better or worse after the operation than before, but this question cannot be answered with certainty. In the aabsence of disease of the labyrinth the condition of the parts around the fenestræ is the main factor influencing the final result as to hearing. Several observers (for example, Politzer, Heine, and Grunert) have given statistics on the subject which show that on an average the hearing is improved in rather less than half the cases, unaltered in about a third, and made worse in the remainder.

Several years ago I tested the hearing in a number of consecutive private cases. The examinations were made from one to seven years after operation. In every case operation thad been done for long-standing otorrhoea with more or less bone disease. The ages of the patients ranger from 14 to 50 years. In all these cases my method of grafting was carried out. About 75 per cent. of these patients showed remarkably good hearing as the result of the operation. I propose at a future time to publish further details about them. In children the hearing after the complete mastoid operation combined with my methor of grafting is usually very good. They may suffer no educational disadvantage, and their deafness may even pass unnoticed while they are at school.

Alternatives to grafting. - The only alternative to grafting I have so far mentioned is tamponning, but we have also the 'method of Baracz, the "blood-clot dressing," Beck's bismuth vaseline paste method, and the use of scarlet red.

In 1900 Baracz, of Lemberg, ${ }^{7}$ published a method he had devised of covering the bone with a flap of skin taken from the neck. This plan has the disadvantage of leaving a scar in the neck, but it can be rapidly carried out and requires less delicate manipulation than does the grafting operation which I recommend. Such a flap as Baracz makes should never be placed over the inner wall of the tympanum, where the thinnest of Thiersch grafts alone are suitable. Those who apply thick slices of tissue over the fenestræ must not be surprised if the hearing of their patients is not improved. I have no personal experience of this method.

The "Blood-clot dressing."-After the mastoid operation a cavity is left in the bone, the walls of which cannot be approximated; if the skin be sutured over this a "dead space" is left which fills with clot. Surgeons have always regarderl such " clead spaces" with considerable distrust, and it was until quite recently generally taught that the presence of blood-clot in such spaces was harmful. Only a few years ago a drainage-tube was considered indispensable even for a clean wound made through healthy tissues, lest blood and serum should accumulate in the wound and prevent healing. In the fifth edition of the late Greig Smith's "Abdominal Surgery," published in 1896, the objection is raised to the method, now so generally in use, of. suturing the abdominal wall in layers, that "such a suture leaves a series of gaps to be filled with clot, between each layer at the line of junction." 8

Further observations showed that this fear of blood-clot in a wound was groundless. So far from exercising a deleterious influence it is an important factor in the process of healing, since the serum from fresh blood-clot possesses bactericidal powers, and the fibrin of the clot forms a delicate scaffolding upon which the new fibrous tissue is built up. In the time of our forefathers it was a common practice, often attended with the most happy results, to allow the wound in a case of compound fracture to become occluded with dried blood, but the reasons why many of these cases did well were not then appreciated. In 1886 Schede $^{9}$ publisher a paper on the Healing of Wounds under a Moist Blood-scab, in which he showed how important a part blood-clot plays in the obliteration of "dead spaces." In 1891 Halsted, ${ }^{10}$ to whom we are indebted for many improvements in surgical practice, ealled attention to the subject and pointed out that not only should clean wounds be as a rule entirely closed, but that suppurating wounds might, with certain precantions, be similarly treated. Among the cases he mentions in support of his views are several instances of bony cavities. In commenting on these he says: "A bone cavity should" never be stuffed. The granulations should be encouraged to grow as luxuriantly as possible. Whether the blood-clot melts away or not the bone cavity should be bridged over by skin or by protective gutta-percha tissue. The granulations must be most carefully protected from insult. They should rarely, if ever, be irrigated. In other words, a bone cavity which has lost its blood-clot should be treated as if it still possessed it." The method adrocated in Halsted's paper for dealing with "dead spaces," which has been termed the "bloodclot dressing," is deliberately to allow the space to become filled with fresh blood, to close it over with skin, if skin be available, or if not to cover the opening with gutta-percha tissue, to place over all a protective dressing, and to let it alone. By this means it is claimed that rapid healing may be obtained in many cases which if treated by the open method would heal much more slowly and with greater deformity.

The success obtained in dealing with other bone cavities by this method has induced several surgeons to use it in mastoid cases; I have, indeed, myself applied it successfully in acute cases. If the "blood-clot dressing" is to be employed no antiseptic must be used, as it is essential to success to have a wound surface of uninjured living tissue.

When $\mathbf{I}$ was in Copenhagen last year I found that Professor Mygind adopted the "blood-clot dressing" as his ordinary method of treating cases of the complete mastoid operation. A week or ten days after the first operation he throws forward the pinna and curettes the cavity. He then allows the cavity to fill with fresh blood, sutures the flap in place, and applies a protective dressing. I do not consider, however, that the results of this method can be compared with the rapid healing obtained by epithelial grafting, and I may add that the results I have obtained from the "bloodclot dressing" in acute cases compare unfavourably with those obtained by the more common surgical methods. Moreover, after the complete mastoid operation the object in view is not to fill the carity nith a mass of cicatricial tissue, but to epithelialise the surface of the cavity as rapidly as possible.

Beck's bismuth paste and scarlet red.-I have found this method most useful in promoting the healing of cavities elsewhere in the body, and I have used it both as a substitute for, and as an adjunct to, grafting in mastoid cases. It outlines the cavity, sterilises its surface, checks exuberant granulations, and does not interfere with the growth of epithelium. It obviates the necessity for skilful tamponning. I make the injection once a week.

Scarlet red.- I have not observed any great advantage from the employment of scarlet red ointment $\uparrow$ in the cavity left by the mastoid operation, possibly because my experience of its use in these circumstances is small. In complicated cases (extradural abscess, sinus thrombosis, \&c.), in which the superficial wound is often large and is designediy left widely open, there is no doubt in my mind that the epithelialisation of the superficial wound and of the edges of the mastoid cavity is much hastened by the use of this ointment. Last month I used the scarlet red ointment with great success in the convalescence of two patients from extradural abscess and cerebellar abscess respectively. The scarlet red ointment should be applied every other day ; on alternate days some other simple dressing.

Grafting in labyrinthine operations. - If I may look forward a little, I think that epithelial grafting will be found useful in hastening the healing of wounds which are now so commonly made in the petrons for the cure of suppurative or non-suppurative conditions. Recent operations for tinnitus and vertigo have been attended with a fair measure of success, and there is some hope that deafness due to obstruction of the fenestræe may some day yield to operation.

Many patients have complete tympanic deafness without any, or with but very slight, evidence of disease of the nerrous apparatus of hearing. In these cases no soundwaves can penetrate the bony box of the internal ear through the normal channels, and it seems possible that aerial conduction might be restored by making an artificial opening in the capsule of the cochlea. 
The operation. The complete mastoid operation is done, the posterior wall of the osseous meatus and the annulus tynıpanicus being especially well cut down so as to get a good view of the inner wall of the tympanum. The mucous membrane of the tympanum and antrum is not disturbed. The stapes is then carefully removed and the little wedgeshaped portion of bone between the fenestræ is cut away with a gonge of corresponding width; the stroke should be gentle and should be directed from above downwards and forwards. The greatest care should be taken that the cutting edge of the gouge does not cross the vestibule and impinge upon its inner wall; a little clear fluid escapes. The opening is immediately covered over by an epithelial graft just large enough to overlap its margins. No further escape of fluid occurs, and healing takes place rapidly and satisfactorily with the usual dressings. An opening so made leads into the vestibule and into both scalæ of the cochlea. Possibly it might be better to open the cochlea directly and avoid opening the vestibule. In a case I published many years ago ${ }^{11}$ suppuration had extended into the semicircular canals, and in removing these the vestibule was widely opened; it was not the seat of suppuration, and clear fluid was seen to escape from it. A graft was placed over the opening into the vestibule. The result was remarkable; not only was the vertigo cured, but the hearing was restored. The patient was a woman, 54 years of age, who had had left otorrhcea since childhood. At the time of operation there was absolute deafness of the left ear, and the patient said she had been deaf in the left ear all her life. The graft over the vestibule was absorbed and replaced by a living membrane which could be identified by a probe passed throngh a speculum. I have always thought that sound waves, in this case, passed through the membrane which had formed over the aperture in the restibule made at the operation, and not through the fenestra. This is another route by which aerial conduction may possibly be restored.

During the last 15 years I have operated on the labyrinth for deafness in a few selected cases, but only in one with any success. I shall try again.

I should like to refer to Jansen's method of epithelial grafting in acute cases, but time does not permit.

History.-For some years before adopting epithelial grafting systematically I had from time to time applied grafts, either at the time of doing the bone operation or at varying periods afterwards, sometimes throngh the unclosed retroauricular wound, sometimes through the meatus. I do not claim priority in the matter of the application of Thiersch grafting, a procedure well known in general surgery, to the mastoid operation. Several German and probably enough other surgeons had made use of epithelial grafts in mastoid operations considerably before my method was published; but I believe that I was the first to advocate the systematic adoption of epithelial grafting for the immediate healing of the bone wound, and that this should be combined with closure of the wound by suture. The account of this method was published in January, 1900.12

A description of 'Thiersch's method of transplanting large epithelial grafts is given in a paper published by Urban of Jeipzis in 1886. ${ }^{13}$ 'The first mention of Thiersch grafting as a part of the complete mastoid operation is, so far as I am aware, in a paper by Siebenmann published in 1893.14 Siebenmann recommended the application of epithelial grafts ( $2 \mathrm{~cm}$. by $5-7 \mathrm{~cm}$.) two or three weeks after the bone operation.

Reinhard, of Duisburg, in $1894^{15}$ endorsed Siebenmann's recommendation, and in $1898^{16}$ wrote more fully on the subject. He had tried immediate grafting in 1893, but soon gave it up on account of the unsuccessful results due, he says, partiy to faulty technique and partiy to selection of unsuitable cases. In the 1898 paper he advised grafting at the first, second, or third dressing after curetting the granulations under an anæsthetic. He held that it was never possible to say with any certainty that all disease had been removed, and that cases in which it was advisable to close the mastoid wound were exceptional. He concludes the paper by saying that he had no doubt that epithelial grafting, notwithstanding its often considerable technical diffculties, would become more and more appreciated, whereby the practice of the radical operation, so beneficent in its results, would no longer be restricted through fear of a jrolonged after-treatment.
In 1897 Alfred Denker, then of Hagen, in Westphalia, ${ }^{17}$ now Geheimrat Professor in Halle, speaking at the German Otological Congress in a discussion following a paper by Nolentius on the mastoid operation, suggested grafting oy the Thiersch method in order to expedite cicatrisation of the open retro-auricular wound. In $1899^{18}$ heread a paper on the subject and advised grafting from the second to the fourth week. He cut a large graft. which, he said, could, with a little practice, easily be done quickly and without an anæsthetic; this he divided with scissors into several portions, which he placed in position by means of Jansen's spatula; any graft over he replaced on the thigh. He left the graft exposed to the air, only placing a small strip of sterile gauze on the floor and in the lower angle of the operation cavity. The operation region was then protected by means of a sort of thimble, which was kept in place by bandages. Several well-known surgeons joined in the discussion on this paper. Siebenmann said that he gave ethyl bromide, or more rarely employed "suggestion narcosis," to curette the granulations and cut the graft, and that he placed the graft in position after the patient had recovered from the narcosis. He advised that the whole surface should be grafted.

Passow said that he found grafting less successful after the burr had been used than when the whole operation had been done with gouge and mallet. In a letter written to mein April, 1904, Professor Passow said: "I employ Thiersch grafts about eight days after the operation, but only if the discharge is small in amount. I have seen no advantage from grafting at the time of the operation."

Rudolf Panse (at the 1899 discussion) expressed doubt as. to the value of grafting and attributed the good results to the second curetting. In a letter written to me in April, 1904, he said: "I consider Thiersch grafting $(a)$ as dangerous if the flaps cover any diseased bone; $(b)$ as unnecessary, for after the removal of all disease healing takes place in six weeks.'

Scheibe (at the 1899 discussion) said that he grafted on the granulations. Jansen advised grafting immediately or at the first dressing. It is evident from the mention of Jansen's spatula, and from Jansen's own remarks at this discussion, that he was one of the pioneers in this field. Stoddart Barr ${ }^{19}$ has quite recently described a method of inserting an epithelial graft throngh the meatus; he cuts the graft under local anæsthesia.

When the gratting should be done.-The graft may in a few selected cases, with advantage, be applied immediately on the conclusion of the operation for removing the disease. To conclude the whole matter at one sitting is certainly most desirable, but as Celsus ${ }^{20}$ said, "Danger is apt to attend" attempts to effect a cure too quickly and too pleasantly."

The operation cavity is never surgically clean and is often very foul, and I think the ultimate result will most often be better if the grafting is postponed for some days and the cavity again curetted. In a few complicated or specially foul cases it may be better to leave most of the wound unsutured in the interval, but ordinarily I close the mastoid wound entirely and apply a light dressing. I do not plug the operation cavity. but have it irrigated twice daily thiongh the meatus with a mild antiseptic solution. When a sufficient interval, usually seven or eight days, has elapsed, the wound is re-opened and the surface of the tympano-antral cavity prepared anew by removing clots and: granulation tissue. No antiseptic, which might destroy living cells, may be employed during the grafting stage In the presence of intracranial complications the graftingoperation is, of course, postponed until the issue of these. dangerous conditions is known. There is no doubt in my mind that the second curetting of the wound is in certain bacterial infections a great advantage. In general surgery such treatment is often employed, and I have found it of conspicuous utility after the mastoid operation when the infection of the soft tissues tends to persist.

Technique.-Epithelial grafting is carried out in precisely the same way whether it follows immediately upon the conclusion of the bone operation or after an interval.

All bleeding having been arrested, the operation cavity is: finally cleansed with hydrogen peroxide and warm sterile saline solution. (Fig. 1.) The skin of the thigh or arm having been previously prepared, a large epithelial graft, as thin as possible, is cut with a hollow-ground razor moistened with warm sterile saline solution. The inner aspect of the 
FIG. 1.

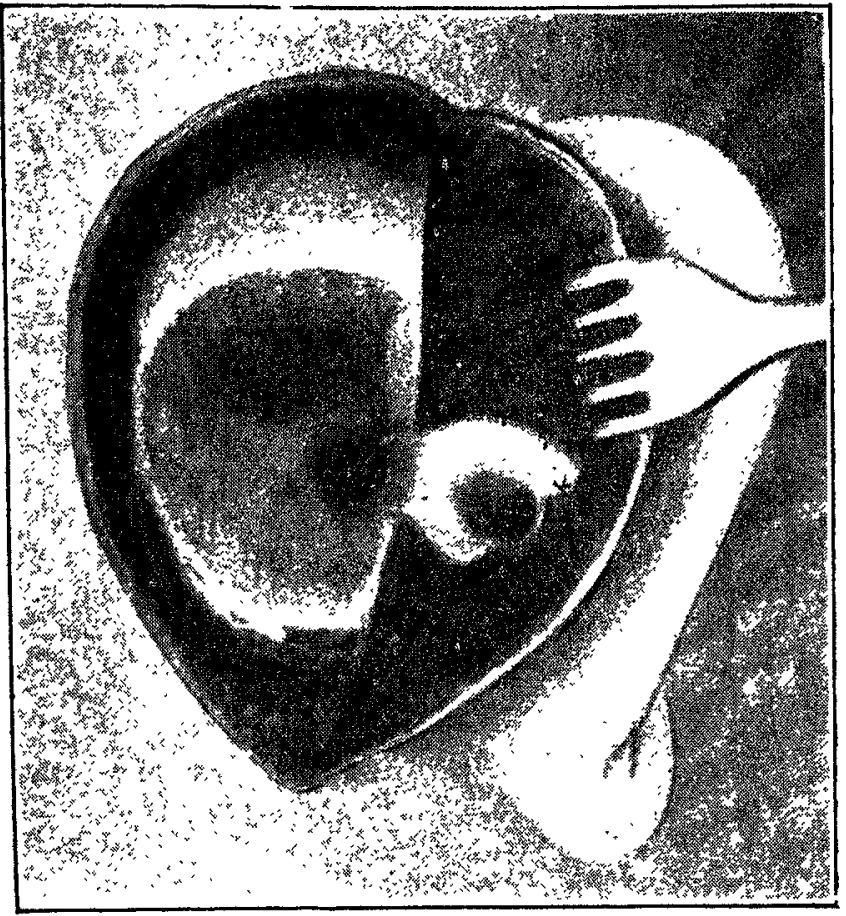

FIG. 3.

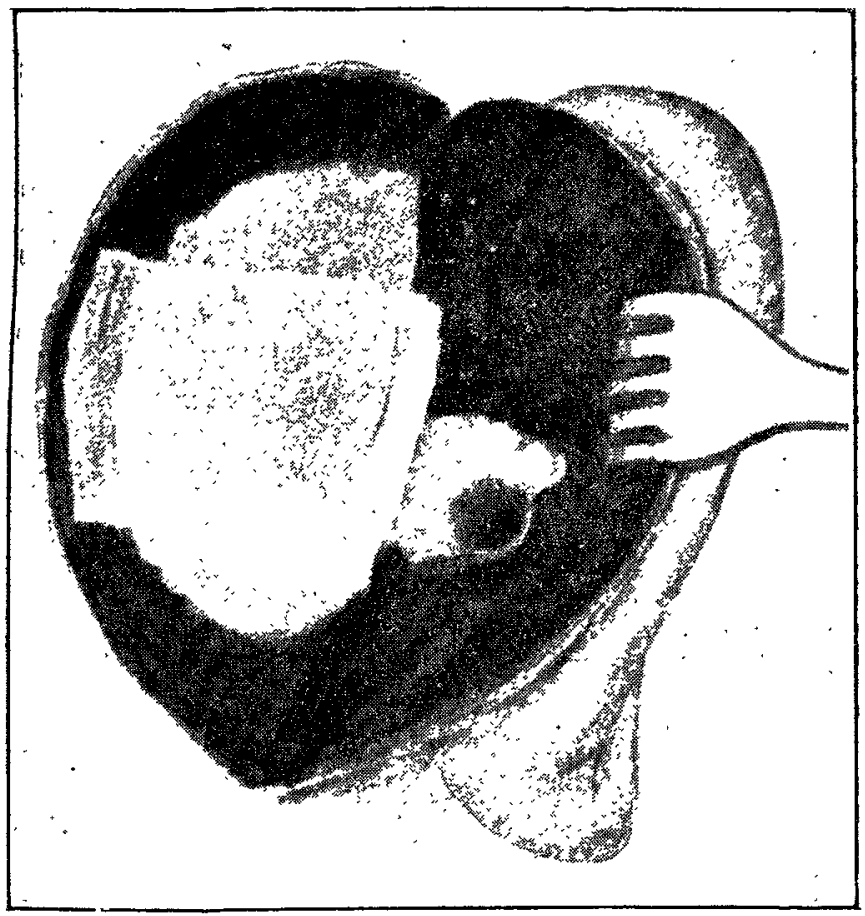

FIG. 5.

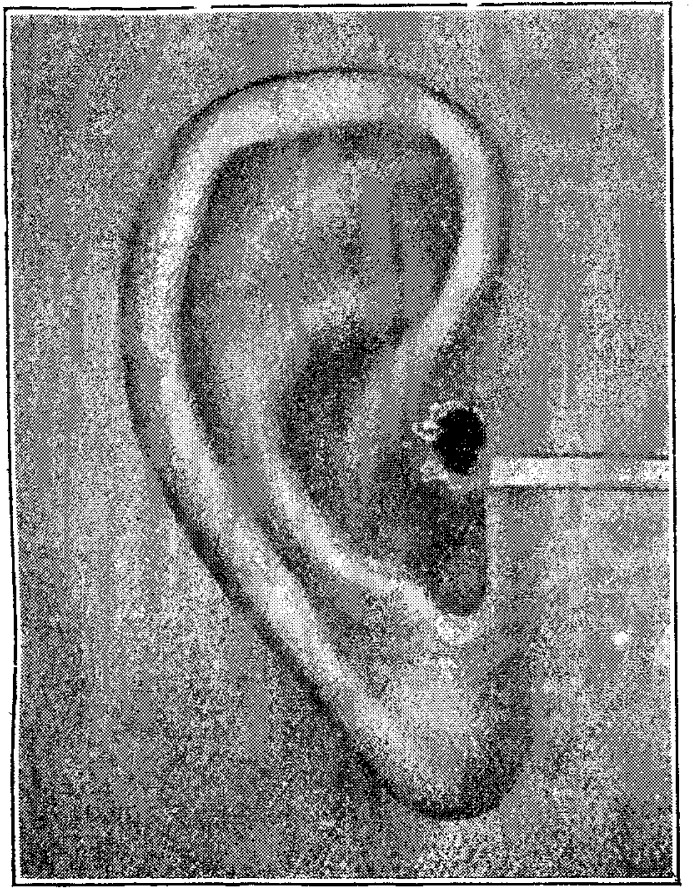

FIG. 2.

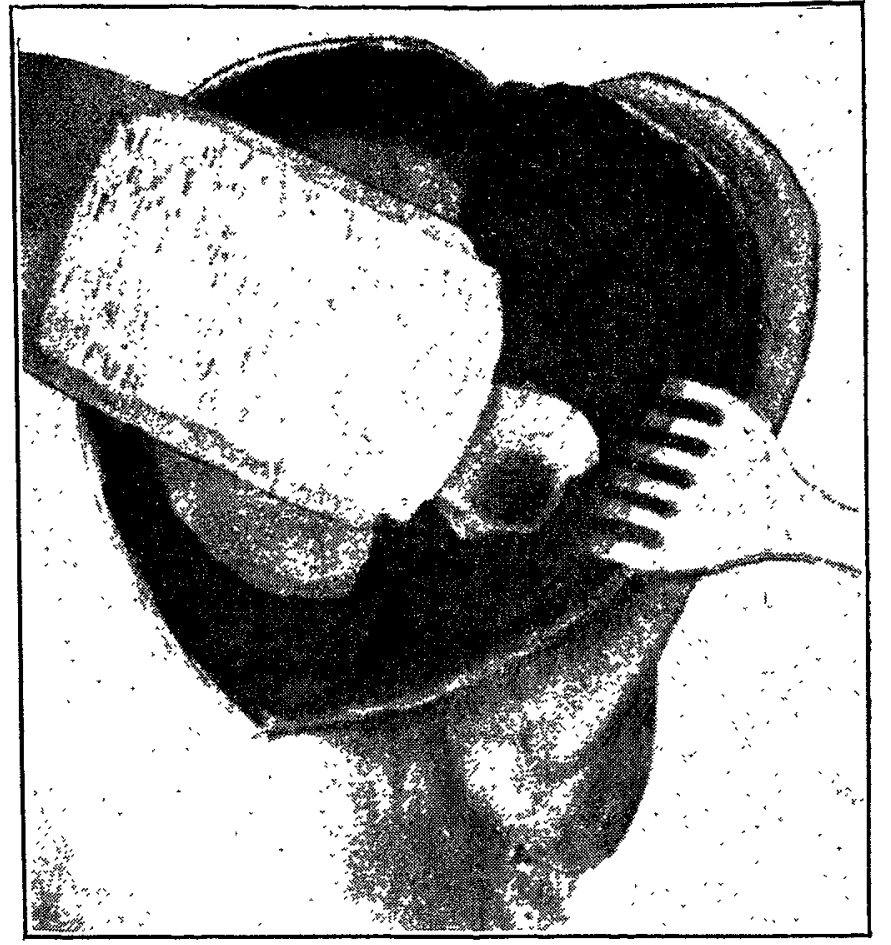

FIG. 4.

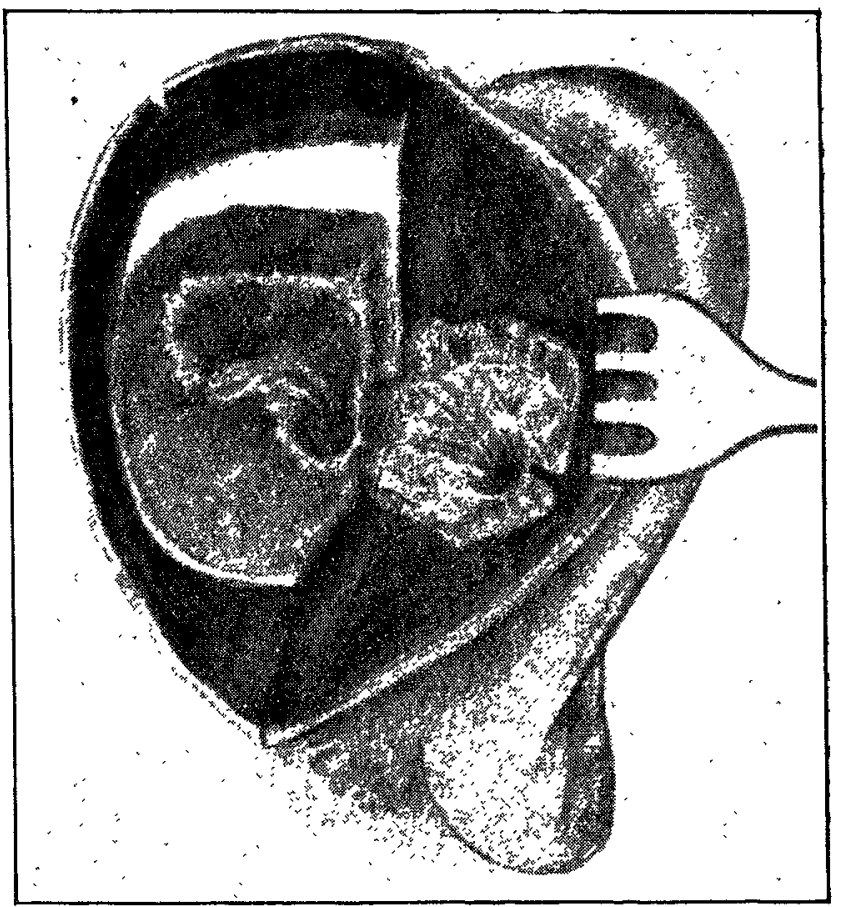

DESCRIPTION OF ILLUSTRATIONS.

FIG. 1-The complete mastoid operation. The meatal flaps above and below, freed from cartilage, are shown stitched to the raw surface of the mastoid flap.

FIG. 2.-Shows the graft on a lifter placed over the bone cavity. The sutures of the meatal flaps have been removed. The bone operation has been performed seven tays previously.

FIG. 3.-Shows the graft Iying over the bone carity, the lifter having been taken away.

FIG. 4.-Shows the graft lying against the walls of the tympano-antral cavities and slightly over-lapping their vertical boundaries. Note that the graft is not allowed to pass below the lower margin of the antrum. On the outer boundary (inner surface of the mastoid flap) two smaller grafts have been applied. Note that a portion of each graft has been coaxed round the edges of the external meatus-the posterior half of which is a raw cut edge.

FIG. 5.-Shows portions of the two grafts on the inner surface of the mastoid flap appearing on the external aspect of the meatus. They are thus caused to cover the raw cut edge which forms the posterior half of the new meatus. 
upper part of the thigh yields as a rule an excellent graft, because here a flat surface of sufficient extent is readily obtained by stretching the skin. A convex surface or a concave surface, such as that over Hunter's canal, gives a graft of varying. thickness. The cutting of a graft sufficiently large and thin requires practice and dexterity, and this is, $I$ believe, the main difficulty in the universal acceptance of the method. 'The skin varies much in different individuals. A coarse skin does not yield a very thin graft; the finer the skin, the thinner and more perfect is the graft. 'The skin! of children yields beautiful grafts.

It is quite easy to cover the roof of the antrum and the attic and the inner wall of the antrum with one graft, but it is more difficult to apply the graft to the inner wall of the tympanum proprium. The graft is best carried to the wound spread out on a microscope-section lifter. These lifters are made of steel nickel-plated and are of various sizes. The front border of the lifter is placed against the outer or superficial edge of the anterior wall of the cavity in the bone made by the operation. (Fig. 2.) The margin of the graft is now coaxed from off the lifter on to this superficial edge, and also above on to the adjoining superficial edge of the roof of the carity, just below the linea temporalis. The upper and anterior margins of the graft thus placed are held in position by a probe. The section lifter is gradually withdrawn and the lower and posterior edges of the graft drop against the posterior and lower boundaries of the operation cavity; the graft thus bridges over the operation cavity. (Fig. 3.) The air and blood which separate the graft from the inner wall of the tympano-antral cavity are removed by a little skilful manipulation, but chiefly by suction through a pipette, insinuated beneath the edge of the graft. 'The graft then clings closely to the raw-bone surface, adapting itself accurately to its eminences and depressions. The graft is now held flat by the atmospheric pressure against (1) the anterior wall of the cavity, formed internally by the anterior boundary of the tympanum and attic, and externally by the anterior wall of the enlarged osseous meatus; (2) the anterior part of the roof of the cavity, formed by the tegmen trmpani and the superior wall of the enlarged osseous meatus; (3) the inner walls of the attic and tympanum; (4) the tegmen antri; (5) the tuberosity formed by the horizontal semicircular canal and the Fallopian canal; and (6) the inner wall of the antrum. (Fig. 4.)

A little bleeding is apt to come from the neighbourhood of the Eustachian tube, and the pipette may have to be used more than once before the graft lies satisfactorily against the tympanic wall. If the tegmen has been removed the graft lies against the dura. It is undesirable to graft the posterior and lower part of a very large mastoid cavity, for this will make the permanent cavity unnecessarily large. Moreover, this part will heal rapidly enough by the approximation of the raw inner surface of the mastoid flap to the granulating bone surface. The main effort should be directed to covering the tegmen, the inner wall of the attic, tympanum, and antrum with epithelium, so that these cavities, which have for years been the site and harbour of disease, may be immediately epidermised.

The graft is held in place against the bone by the application of small, dry, sterile, cotton-wool mops or a strip of narrow ribbon gauze dusted with a non-irritating antiseptic powder, such as aristol. If the little plugs are used the first is placed in the lower part of the tympanum and often extends into the upper part of the Eustachian tube, the next is placed against the upper part of the inner wall of the tympanum and attic, and the next against the inner boundary of the aditus and antrum. About seven plugs are usually employed. A piece of sterilised gauze is then placed over all to prevent displacement. The little cotton-wool mops are held in angular forceps and pushed home by a steel probe or stopper, the smooth head of which prevents any chance of the graft clinging to the stopper as it is removed. One or two grafts are placed on the outer boundary of the operation cavity-namely, the inner surface of the mastoid flapcorresponding in extent to the tympanum, attic, and antrum. (Fig. 4.)

It is a good plan to arrange a portion of these external grafts so as to cover the raw edge of the posterior margin of the meatus, for here the cartilage is exposed without a complete skin covering. The edges of these grafts are thus inveigled through the meatus and appear on the skin surface of the concha. (Fig. 5.) The mastoid tlap is replaced and sutured with fine silkworn gut. A thin gauze mop is placed in the meatus to support the grafts against the raw posterior edge of the meatus and a dry sterilised dressing is applied. The external dressing should be renewed daily. The plugs are removed with forceps from the third to the sixth day. This procedure is painless, as the raw bone is protected by the graft. The subsequent treatment consists in irrigation with hydrogen peroxide and rectified spirit twice a day or in dry gauze tamponning as often as may be thought desirable. When the dead part of the graft has come away the cavity, on careful inspection, is seen to have a smooth pink surface which is, in fact, a surface of epithelium and no longer a raw surface of granulations. In the course of a few days the colour of the surface changes from pink to pearly grey, showing unmistakeably that the grafting has been successful. The last place to heal is a cartilage granulation which usually presents just inside and behind the lower margin of the meatus. If tamponning is employed, sterilised ribbon gauze half or one inch in width is well adapted to the purpose. It may be impregnated with a mild astringent such as aluminium acetate. Iodoform gauze should not be used, as it promotes flabby and exuberant granulation.

Victor Hugo" 1 said: "Every new offspring of science presents this double aspect, monstrosity as fotus: wonder as germ." The history of all great operations is the same. Pathology was for long in advance of surgery, and a germ from which after long years a scientific operative procedure was evolved often at first gare rise to a monstrosity of an operation. The mastoid operation is no exception; it commenced with crude and imperfect efforts and at length reached a stage free from danger and death and in our day is conducted upon " a plan leading direct to the end desired." 22 We must not on this account rest satisfied with our present methods and results; "while anything remains to be accomplished," observed a great statesman, "nothing is done." The mastoid operation will be still further improved. "Look one step onward and secure that step," said Paracelsus. ${ }^{23}$ In the attempt to follow that advice this paper has been written.

Bibliography.-1. Whiting, Frederick : The Modern Mastoid Operation, p. 255. 2. Politzer, Adam: Lehrbuch der Ohrenheilkunde, fourth edition, 1901, p. 470. 3. Encyklopädie der Ohrenheilkunde (Blau), 1900, p. 234. 4. Leber die retroauriculare Oeffnung nach der Radicaloperation chronischer Mittelohreitenungen, Zeitschrift fuir Ohrenheiloperation chronischer Mittelohreitenungen, Zeitschrift fuir Ohrenheil-
kunde. Band xxxii., pp. 215, 216, and 223.5 . Ballance, C. A.: kunde, Band xxxii., pp. 215, 216, and 223. 5. Ballance, C. A.:
Transactions of the Poyal Medical and Chirurgical Society, vol. Ixxxiii. Transactions of the Royal Medical and Chirurgical Society, vol. Ixxxiii.
6. Siehenmann: Berliner Klinische Wochenschrift, 1893, No. 1 and 6. Siehenmann: Berliner Klinische Wochenschrift, 1893, No. 1 and
No. 23. Reinhard : Versammlung deutscher Naturforscher und Aertze in Düsselilorf, 1898. Jansen: Ibid. 7. 7 . von Baracz: Deutsche Zeitschrift für Chirurgie, vol. 1v., 1900, p. 120. 8. Greig Smith : Abdominal Surgery, fifth edition, vol. i., p. 110. 9. Schede, M.: Ueher die Heilung von Wumlen unter dem feuchten Blutschorf, Verhandlungen der Deutschen Gesellschaft für Chirurgie. 1886, p. 62. 10. Halsted: The Johns Hopkins Hospital Report, 1891, vol, ii., p. 255. 11. Ballance, C. A.: Transactions of the Otological Society, vol. i. $(1900)$, p. 47 . 12. Ballance, C. A. : Transactions of the Royal Merlical and Chirurgical Society. 1900, vol. Ixxxiii. 13. Deutsche Zeitschrift für Chirurgie, 1886, p. 188. 14. Siebenmam, F.: Berliner Klinische Wochenschrift, 1893 No. 1. 15. Reinhard, Karl: Archiv für Ohrenheilkunde, 1894 vol. xxxrii., p. 110. 16. Ibicl.. 1898, vol. xlv., pp. 186-192. 17. Denker p. 154. 18. Ibid., 1899, p. 93. 19. Manual of Diseases of the Ear,
T. and S. Barr, fourth edition, 1909, p. 139. 20. Celsus: Liber III., T. and S. Barr, fourth edition, 1909, p. 139. 20. Celsus: Liber III, 22. Carlyle: Frederick the Great, Book IV., chap. 10. 23. Paracelsus:
Scene I.

\section{ADDENDA.}

I.

Mr. Sydney R. Scott, aural surgeon to St. Bartholomew's Hospital, has sent me an interesting letter on the subject of mastoid and labyrinthine grafting:-

I am very pleased to tell you my riewrs and 24th June, 1912. rafting in connexion with the radical mastoid and experience of skinthis experience is compared with what yours must be. The small though case which I grafted some fire years ago was one of malignant disease, in which there was an unusually large excavation of the temporal bone. During the last three or four years I have macle a rule of grafting every case as a part of the regular procedure of the radical mastoid operation, not at a subsequent stage, but at the same time as the mastoid operation. This immediate grafting undoubtedly hastens healing in a remarkable way, so that, instead of having to keep patients under close daily observation for four to six weeks, one can allow them to leave after the second week, and subsequently
they require very little attention apart from the precautions they require very little attention apart from the precautions against proliferating granulations, from some spot which may hare escaped the graft. The economic result, as regards hospital patients, has been that many more can be passed through the few beds which are allotted for mastoid surgery, since the adoption of immedis.
grafts, than was possible in the days when no grafts were applied.

grafts, than was possible in the dass when no grafts were applied.
I take it that the object of grafting is to obtain a more rapid healing I take it that the object of grafting is to obtain a more rapid healing of the surface of the cavity than is possible without grafts. Incidentally used sometimes to be noticed before grafting was adopted. Generally 
speaking, I have not found age any contra-indication. It is sometimes convenient to take the graft from another person in the case of an infant or when there is much wasting.

I employ the immediate graft whether suppuration exists or not. In

I employ the immediate graft whether suppuration exists or not. In
cases of extradural abscess complicating chronic otitis for which one performs the radical mastoid operation, I employ a graft, and close the post-aural incision, just as one does in uncomplicated cases. Whether the whole of the graft adheres or only a portion of it, I am convinced of the saving of considerable time in the healing process.

Again, in cases of post-operative suppuration where the immediate graft was applied the graft is not necessarily destroyed by the infective inflammation; even in quite unpromising-looking cases (which are fortunately not common) a considerable portion

found to have adhered as the reaction subsides. Coming to labyrinth cases, I have no reason for not grafting over a simple fistula of the external semicircular canal when the labyrinth is functionating, but when a fistula of the labyrinth is accompanied by acute infective labyrinthitis, it is, in my opinion, not permissible to graft without first securing adequate drainage of the vestibule, and even then it is questionable whether a graft over the opened labyrinth is advisable. In such cases, and generally in operations on the labyrinth, when relatively deep-seated pockets have been made into the labyrinthine capsule, and are bridged across by the tacial nerve (as, for instance, in extirpation by the double route of vestibulotomy), it is better to limit the graft to the meato-mastoid portion of the cavity, leaving the labyrinthine cavities to become filled by reparative material, and this soon becomes epithelialised if one can prevent proliferation beyond the general level of the grafted surface.

Nor should I employ a graft over the labyrinth if the internal auditory meatus has been opened, as indicated by the escape of cerebro-spinal fiuid, believing this escape of fluid acts as a safeguard and tends to prevent leptomeningitis. I have no objection to applying a graft to the meato-mastoid part of the cavity in such cases.

To discuss the important question of the effect of grafting on the acuity of hearing would necessitate looking up a long series of cases, in order to give exact details. I must be content with saying that 1 avoid applying grafts to the inner tympanic wall in cases in which useful hearing has survived the prolonged suppuration, but when great hesitate to graft over the promontory and fenestræ.

\section{II.}

My colleague, Mr. H. J. Marriage, aural surgeon to St. 'Thomas's Hospital, has sent me the following account, which is eminently practical, of his experience of epithelial grafting :-

June 28th, 1912. my practice for the last five $r e$ the grafting of mastoids, it has been drease to graft the carity at the tim in cases of chronic mastoid but in cases of acute mastoid disease where the radical operation is necessary, I do the grafting about a week or ten days after the primary operation.

The method $I$ have adopted in the chronic cases is to thoroughly remove all trace of disease, then clean out the cavity with hydrogen peroxide ( 20 vols.) and apply one large graft which should be very thin. The graft is got into position by sucking out the air beneath in the mainer which was first recommended by you, and is kept in in the maimer which was first recommended by you, and is kept in its place by one long sterilised plug of plain gauze $\frac{1}{2}$ inch in width, graft ; the end of the plug is brought out of the meatus, and the graft graft; the end of the plug is brought out of the meatus, and the graft to cover the cut edge of the meatal wall, and form a complete covering to cover the cut edge
for the entire cavity.

for the entire cavity.
At first I used to leave the plug in for seven days, but now find that five days is sufficient for the graft to become adherent. After the removal of the plug the ear is syringed out daily with a weak solution of hydrogen peroxide, and a small piece of gauze put in to absorb the diswharge; this is carried on for six or seven days, and afterwards patients are given hydrogen peroxide $(10$ vols.) to drop into the ear twice daily. The primary grafting, in addition to saving the patients the trials of a second operation, considerably shortens their stay in hospital, as usually they are able to leave at the end of about 12 days ; it also saves them the pain of constant firm plugging, and is much less troublesome to the surgeon, as after they leave hospital it is only necessary for them to come up once a week for inspection and for the cauterisation of any small granulating areas which may be present. The majority of any small granulating areas which may be present. the majority of cases are healed by the end of six weeks, the last place

Even when it has been necessary to expose the dura of the middle Even when it has been necessary to expose the dura of the middle
and posterior fossa, I apply a primary graft, as it grows on the cura and posterior fossæ, I apply a primary graft, as it grows on the cura
extremely well. I have also grafted in the same way a dozen cases in which there was a bony fistula in the external semicircular canal with which there was a

One case, a lady of 35 , who had had otorrhoea for over 26 years, was sent to me as possibly a case of cerebellar abscess, as she had violent headache and very marked vertigo and was quite unable to walk straight. I diagnosed a fistula of the semicircular canal, and at the operation found that she had a large cholesteatoma which had eaten away the arch of the horizontal semicircular canal. I cleared away all the disease and applied one large graft in the usual way, and within six weeks the cavity was completely healed. About two months later I happened to meet her at a dance, and was able to prove for myself that she could dance through a long valse without any trace of giddiness. The operation was done four years ago, and there has been no recurrence of the disease or of the vertigo.

Graduation IN THE University of Vienna.-

During the past academical year 960 students have received the degree of Doctor in the University of Vienna. Of these, 25 belonged to the theological faculty and 456 to the legal, all of whom were men. The philosophical faculty promoted 200 men and 22 women, and the medical 247 men and 10 women.

\section{THE OPERATIVE TREATMENT OF*SIMPLE FRACTURE OF THE LONG BONES IN CHILDREN.}

By H. H. SAMPSON, M.B., B.Ch. BiRm., F.R.C.S. ENG.,

CASUAITY OFFICER, HOSPITAL FOR SICK CHILDREN, GREAT ORMOND-STREET, W.C.

A SUFFICIENT period has now elapsed since $\mathrm{Mr}$. W. Arbuthnot Lane commenced operating on simple fracture at the Hospital for Sick Children, Great Ormond-street, to enable the end-results of his treatment to be collected and put upon record. It was in 1893 that $\mathrm{Mr}$. Lane inangurated a new departure in surgery by fixing the fragments in a simple fracture of both bones of the leg. ${ }^{1}$ 'The first operation for simple fracture at the Children's Hospital was performed in 1907. Since that date 104 cases of fracture have been treated, and 72 submitted to open operation.

For the sake of clearness the subject-matter has been divided into sections, and at the outset opportunity is taken to review the principles which guide us in the treatment of fractures.

The principles of fracture radiography. - The introduction of the Roentgen rays marks an important epoch in the treatment of fractures. The proceeding known as "setting a fracture" can now be judged on its merits. But radiography must not be regarded as infallible; unless certain principles are borne in mind a false idea of the condition may be deduced. A single view merely indicates that a fracture is present; it is quite useless as an indication of the amount of displacement of the fragments. For this, two views taken in planes at right angles to each other are necessary in every case. Indeed, only when one view shows the fragments superimposed will the second picture indicate the full degree of displacement present (see Figs. 1 and 2). In children the transparent nature of the epiphyses introduces a special difficulty into the correct interpretation of radiograms. In such cases it is essential to have corresponding views of the sound limb.

The arguments in favour of operative treatment.-It is obvious that the unsatisfactory results of conservative measures can be the only justification for operative treatment.

Mr. T. Clinton Dent in 1908 wrote $^{2}:-$

Fracture of the leg, involving the knee or ankle joints, or fracture of the femur uniformly leads to permanent unfitness for the work that devolves on these men (police), fractures occurring in the neighbourhood of these joints nearly always have the same result ...... My experience with regard to fracture of the leg has led to the expression of rather gloomy, perhaps pessimistic, views.

Mr. E. W. Hey Groves, at the Surgical Section of the British Medical Association in 1910, is reported as having said $^{3}$ :-

As judged by their after-history, cases of simple fracture of bones of the leg treated by non-operative measures showed very poor results, but there was not yet available a similarly extensive series of cases reated by operative means to effect a just comparison.

Mr. H. J. Paterson at the same meeting said ${ }^{3}:-$

Referring to results of fractures of both bones of the forearm, followed up some years back, it was found that in no single instanco in which there had been a fracture of both bones of the forearm had th patient regained his full range of pronation and supination.

These expressions of opinion should be sufficient to convince anyone that the conservative method, after years of undisputed sway, has entirely failed to produce satisfactory results. Proceeding now to inquire why these results are so unsatisfactory, we naturally wonder whether displacement of fragments in a fracture can be reduced by the usual conservative measures. Referring again to the British Medical Association Meeting in 1910, Dr. E. W. H. Shenton said :-

In the observation of a verp large number of fractures it became clear that fractures were practically never replaced in perfect position by external manipulation.*

We have now to consider whether accurate coaptation of fragments is necessary. If we regard the bony skeleton as the crystallisation of lines of force, the structure and configuration of the long bones become a subject of the highest

Transactions of the Clinical Society, vol. xxvii., 1894. Clinical Journal, Oct. $7 \mathrm{t}, \mathrm{h}, 1908$. 3 Brit. Mer. Jour., vol. ii., 1910.

G 2 